
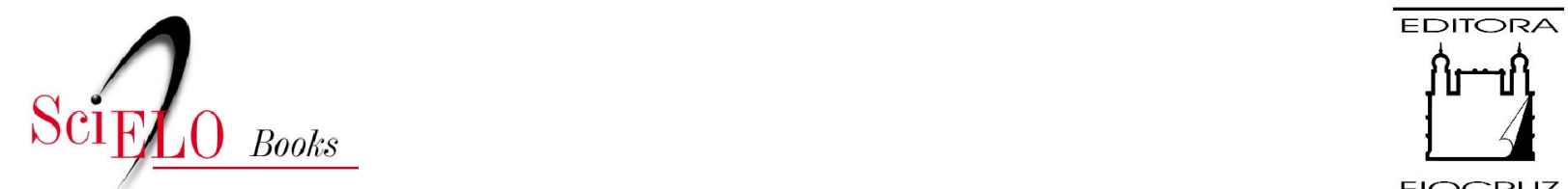

FIOCRUZ

\title{
4 - Referencial de análise para repensar as políticas e futuras estratégias de intervenção
}

\author{
Romulo Maciel Filho \\ Maria Alice Fernandes Branco
}

\section{SciELO Books / SciELO Livros / SciELO Libros}

MACIEL FILHO, R., and BRANCO, M. A. F. Referencial de análise para repensar as políticas e futuras estratégias de intervenção. In: Rumo ao interior: médicos, saúde da família e mercado de trabalho [online]. Rio de Janeiro: Editora Fiocruz, 2008, pp. 83-157. ISBN: 978-85-7541-601-3. Available from: doi: 10.7476/9788575416013.006. Also available in ePUB from: http://books.scielo.org/id/64g49/epub/maciel-9788575416013.epub.

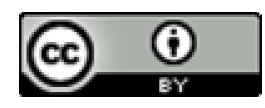

All the contents of this work, except where otherwise noted, is licensed under a Creative Commons Attribution $\underline{4.0 \text { International license. }}$

Todo o conteúdo deste trabalho, exceto quando houver ressalva, é publicado sob a licença Creative Commons Atribição 4.0.

Todo el contenido de esta obra, excepto donde se indique lo contrario, está bajo licencia de la licencia Creative Commons Reconocimento 4.0 . 


\section{4 \\ Referencial de Análise para Repensar as Políticas e Futuras Estratégias de Intervenção}

A finalidade deste capítulo é oferecer um referencial de análise para a distribuição e a fixação de médicos, construído a partir de cinco eixos analíticos para repensar as políticas e futuras estratégias de intervenção, aqui entendidas como mecanismos para desenvolver as relações de cooperação, promover a distribuição de poder, organizar o uso de recursos e transformar a situação dominante que se deseja modificar, de forma a realmente concretizar seu valor estratégico.

O objetivo é evidenciar os fatores e condicionantes que interferem na distribuição e fixação de médicos e identificar possíveis estratégias de intervenção que podem ser aplicadas à realidade brasileira, no contexto das políticas públicas.

O mote para essa discussão é a compreensão de que a forte concentração geográfica dos profissionais e dos serviços impede a concretização dos princípios que regem o Sistema Único de Saúde (SUS), particularmente no que se refere à universalização, à integralidade e à própria descentralização.

A gestão do SUS impõe o enfrentamento do problema da má distribuição e fixação de médicos, o que exige que as questões referentes à condução do trabalho e da educação na saúde sejam colocadas no mesmo grau de importância da descentralização, do financiamento e do controle social.

\section{A Dimensão Política}

A Política Nacional de Gestão do Trabalho e da Educação na Saúde é recente, e seu processo de implantação ainda é incipiente. Construída coletivamente e aprovada pelo Conselho Nacional de Saúde e pela $12^{\text {a }}$ Conferência Nacional de Saúde, em 2003, e considerada um 
instrumento indispensável para a consolidação do SUS, essa política se fundamenta na aplicação dos Princípios e Diretrizes para a Gestão do Trabalho no SUS (NOB/RH-SUS), conjunto de orientações políticas e gerenciais referentes à Gestão do Trabalho, ao Desenvolvimento dos Trabalhadores, à Saúde Ocupacional para o Trabalhador da Saúde e ao Controle Social na Gestão do Trabalho no SUS (Brasil, 2005a).

Como instrumento para assegurar sua implantação, foi criada, no âmbito do Ministério da Saúde, no mesmo ano, a Secretaria de Gestão do Trabalho e da Educação na Saúde (SGTES), que desde então vem promovendo, paulatinamente, ações, iniciativas e intervenções orientadas por esses princípios e diretrizes, que visam ao alcance de propósitos como a implantação de Plano de Carreira, Cargos e Salários (PCCS), educação permanente em saúde e reconhecimento das Mesas de Negociação do Trabalho (Brasil, 2005b).

Ainda que todos os pontos contemplados sejam essenciais e atendam a necessidades antigas, a política de recursos humanos em saúde deve não apenas ser coerente com a política nacional de saúde, mas deve refletir também o espírito e as expectativas da política de desenvolvimento geral do país.

As necessidades e prioridades de saúde, as tendências demográficas, o desenvolvimento social e econômico, os perfis epidemiológicos, as previsões financeiras de curto, médio e longo prazo são fatores que precisam ser considerados na definição dessa política. Afinal, o avanço nas condições de saúde de uma população só se torna permanente quando está alicerçado em medidas mais profundas e consistentes, que enfrentam as restrições impostas pelo contexto econômico e social.

O país não alcançará resultados duradouros e consistentes no que se refere à distribuição e fixação de médicos se o problema continuar sendo tratado como atinente apenas ao campo da política de saúde e, conseqüentemente, da política de recursos humanos em saúde. Mesmo considerando, como o fazem Dussault e Franceschini (2006), que as intervenções que podem alterar a base econômica, política e social inerente ao problema e levar a resultados sustentáveis são de longo prazo, não se pode usar esse argumento para justificar um eterno imobilismo.

A evidente dimensão política e multissetorial do problema da distribuição geográfica de médicos e da fixação desses profissionais ressalta sua forte relação com a necessidade de mudanças culturais, 
sociais e econômicas, que precisam contemplar desde as dificuldades de acesso da população aos serviços de saúde até a formação dos profissionais, a realidade socioeconômica, o corporativismo, a política governamental, o processo educacional, os referenciais socioculturais, dentre outros aspectos. Tais aspectos ao mesmo tempo em que interferem na falta de resultados da política de saúde para lidar com a má distribuição e fixação de médicos também podem ser considerados norteadores da necessidade de ações políticas mais abrangentes que insiram o problema no contexto devido, deixando de tratá-lo como restrito ao campo da saúde.

Como já visto, há clara relação entre os fenômenos macrossociais da intervenção estatal na atenção médica, no mercado de trabalho para os médicos e nas formas específicas de organização da prática médica e do ensino da medicina.

Além disso, como também já discutido, a alta concentração de médicos nos centros urbanos e sua má distribuição pelo restante do território nacional estão diretamente ligadas às desigualdades socioeconômicas e regionais, conseqüências diretas do baixo investimento público e privado nas áreas mais carentes.

A grande concentração regional do Produto Interno Bruto (PIB) e os demais fatores políticos, sociais e econômicos que determinam o subdesenvolvimento dessas regiões exigem estratégias inseridas não apenas na política de saúde, mas nos planos de desenvolvimento econômico do país.

Para facilitar a integração da política de saúde e, mais especificamente, da política de recursos humanos, aos planos de desenvolvimento socioeconômico de um país, Nogueira e Brito (1986), já há duas décadas, chamam a atenção para algumas medidas que devem ser consideradas: 1 ) desenvolver a capacidade de diagnosticar e analisar a situação atual e as tendências de médio e longo prazo; 2) estabelecer mecanismos para acompanhar e prever o comportamento dos recursos humanos em saúde; 3) considerar tanto os fatores da produção (formação) quanto da utilização no mercado de trabalho (emprego); 4) atentar para a demanda gerada pela estrutura dos serviços de saúde; 5) criar sistemas de informação em recursos humanos, como parte dos sistemas de informação em saúde, que considerem a oferta e a demanda de pessoal; 6) utilizar a informação para alimentar estudos de análise conjuntural e de tipo prospectivo. 
Isso permitiria que os governos efetuassem avaliações estratégicas para contemplar não apenas os objetivos da política de saúde, mas as prioridades de alocação de recursos dentro e fora do setor saúde, em função das necessidades sociais e de saúde da população.

As políticas públicas devem ser criadas como resposta do Estado às demandas da sociedade e expressar compromissos da atuação governamental, por meio de uma linha de ação coletiva, destinada à concretização de direitos sociais. É necessário que o problema da distribuição e da fixação de médicos seja inserido na agenda e tratado no âmbito de uma política de Estado, devendo ser objeto de políticas e intervenções, de caráter multi e intersetorial, que integrem os diversos ministérios.

Dada a própria intersetorialidade da política social, quando se almejam determinadas metas para um setor, pode ser preferível investir em outro, o que em alguns casos tende a acarretar maior impacto e melhores resultados (Cohen \& Franco, 2004). Seria o caso, por exemplo, de investir na redução dos fatores que acarretam má qualidade de vida para a população dessas regiões e que não proporcionam as condições adequadas para o exercício profissional da medicina, desestimulando a opção do profissional em atuar nessas áreas. Uma das possíveis estratégias seria criar incentivos para estimular empreendimentos em diversos setores da economia, nas áreas mais carentes e desfavorecidas.

Vale lembrar que o Projeto Rondon ${ }^{14}$ - em que pesem as críticas que possam ser feitas a diversos de seus aspectos - contemplou diferentes operações e programas, vinculados a um grande eixo denominado 'desenvolvimento', não restringindo suas estratégias de intervenção à interiorização de profissionais. O próprio Piass também não se restringiu a esse aspecto, tendo surgido como parte de um plano nacional de desenvolvimento, que estipulava a integração das ações de saúde aos programas de desenvolvimento como condição necessária para o crescimento econômico e social do país. Deve-se recordar que a execução do Piass esteve a cargo das secretarias estaduais de saúde, com a participação das companhias estaduais de saneamento, das secretarias de obras, das prefeituras e de organizações comunitárias.

14 Apresentado no capítulo 2, assim como os programas citados logo a seguir: Programa de Interiorização das Ações de Saúde e Saneamento (Piass), Programa de Interiorização do Sistema Único de Saúde (Pisus) e Programa de Interiorização do Trabalho em Saúde (Pits). 
Por sua vez, o Pisus e o Pits foram concebidos como programas restritos de interiorização, com gestão limitada ao Ministério da Saúde, características estas que se mostraram determinantes para o rumo, também restrito, limitado, pouco consistente e duradouro, dessas duas iniciativas.

Além disso, como já discutido nos capítulos iniciais, as intervenções do Estado no campo mais geral da economia acarretam conseqüências para o próprio mercado de trabalho médico. ${ }^{15} \mathrm{~A}$ ação do Estado produz

repercussões na contenção ou ampliação do emprego no setor saúde, bem como nas políticas de saúde e na organização dos serviços. (...) No caso do mercado de trabalho em saúde, vários estudos indicam a sua dependência quanto às formas de intervenção estatal no setor e aos ciclos de expansão econômica. (Paim, 1994: 6-10)

Especialmente porque, além do modelo de atenção à saúde atuar decisivamente sobre a demanda e a composição da força de trabalho, é o setor público que ocupa hoje, no país, o primeiro lugar como empregador na área da saúde. E essa influência não se dá apenas no que se refere a maior ou menor oferta de postos de trabalho, mas também quando políticas de contenção de gastos públicos acarretam piora das condições de trabalho e de remuneração (Paim, 1994).

O mercado de trabalho médico não se define a partir de variáveis estritamente econômicas, como oferta, demanda, preços, quantidades, produtividade e outras. Trata-se de um mercado atípico, ou ainda de vários mercados atípicos, diferenciados pelo mecanismo financiador do processo de produção de atenção médica no qual o profissional está inserido.

Um exemplo das possibilidades de intervenção do Estado no mercado de trabalho e que diz respeito especificamente ao enfrentamento da má distribuição geográfica de médicos é a estratégia implementada em British Columbia, Canadá. A Comissão de Serviços Médicos (Medical Services Commission) limitou o número de médicos autorizados a trabalhar nos centros urbanos, autorizando, em contrapartida e prontamente, solicitações para atuar em áreas rurais.

15 Zurn et al. (2002) discutem a definição e natureza dos desequilíbrios do mercado de trabalho em saúde, incluindo os desequilíbrios geográficos. Os autores propõem uma base analítica (analytical framework), que considera projeções de demanda e de oferta da força de trabalho em saúde, revisa os indicadores desses desequilíbrios e oferece uma tipologia para classificá-los. 
A medida gerou muita oposição, inclusive no poder Judiciário, e criou grande relutância nos profissionais em se candidatar às áreas rurais por receio de não poderem retornar depois para as cidades de maior porte (Gilmore, 1985; Page et al., 1992).

Em nosso país, é o PSF que tem sido estimulado pelos governos como um novo mercado de trabalho, com potencial para reduzir a má distribuição de médicos e ampliar a fixação desses profissionais.

No entanto, embora, atualmente, possamos dizer que não há crise de oferta de postos de trabalho para a categoria médica, havendo até um crescimento, em especial no setor público, com a expansão da atenção básica via implantação do PSF, essa expansão do mercado, por si só, não conseguirá reverter os desequilíbrios regionais historicamente acumulados (Maciel Filho \& Pierantoni, 2004).

Sem dúvida, o PSF se apresenta como uma modalidade de intervenção com grande potencial de ampliar o acesso à atenção básica nas diversas regiões do país, causar impacto na configuração do mercado de trabalho e na própria formação de profissionais para o setor. Mas, como foi possível observar no estudo realizado pelo Conselho Federal de Medicina (CFM, 2004), comentado no capítulo 1, grande parte dos médicos avalia que, com a implantação do PSF, não se alteraram as condições de trabalho $(54,2 \%)$, a qualidade dos serviços $(44,6 \%)$ e a organização dos serviços $(44,1 \%)$. Da mesma forma, ainda no estudo do CFM, os três primeiros fatores citados pelos médicos como indispensáveis para assegurar a eficácia do PSF foram as condições de trabalho $(81,8 \%)$, a remuneração $(77,7 \%)$ e a infra-estrutura $(77,1 \%)$.

Entende-se que o PSF é uma estratégia bem estruturada e bem aceita tanto pela população quanto pelos profissionais de saúde e pelos gestores, sendo, inclusive, atrativa como mercado de trabalho para os médicos que se propõem a participar de iniciativas de interiorização, como mostram os diversos depoimentos de participantes do Pits. Contudo, há inúmeros municípios que não conseguem oferecer as condições mínimas para o bom funcionamento do Programa ou, em muitos casos, sequer para sua implantação. Dados de estudos como o do CFM (2004) e da pesquisa Perfil dos Médicos e Enfermeiros do Programa Saúde da Família no Brasil (Machado, 2000), segundo a qual o tempo médio de permanência de grande parte dos médicos no PSF é de menos de um ano, reforçam essa constatação. 
A diversidade de vínculos, níveis salariais e direitos trabalhistas que se verifica no PSF estimula essa alta rotatividade e dificulta a fixação dos médicos. Para que esse cenário possa ser efetivamente enfrentado deve-se ter em mente que as peculiaridades da gestão do trabalho em saúde

exigem ações governamentais intersetoriais mais ampliadas envolvendo o Legislativo, o Judiciário e o financiamento do setor, entre outros, que permitam, para além da expansão do mercado, o estabelecimento de condições adequadas de trabalho e emprego para os profissionais de saúde. (Maciel Filho \& Pierantoni, 2004: 159)

Nesse sentido, três importantes estratégias indispensáveis para alterar este quadro já integram a recente Política Nacional de Gestão do Trabalho e da Educação na Saúde, que são: 1) o Programa Nacional de Desprecarização do Trabalho no SUS; 2) a Comissão Especial para a Elaboração de Diretrizes para um Plano de Carreira, Cargos e Salários para o SUS; 3) as Mesas de Negociação Permanente do Trabalho no SUS. Por serem extensivas a todo o SUS, tais estratégias dependem, inevitavelmente, da articulação política e técnica entre as esferas federal, estadual e municipal. Sua implantação poderá funcionar como um verdadeiro 'divisor de águas' no encaminhamento dos principais problemas hoje existentes na gestão do trabalho no SUS.

Pensando na questão da má distribuição e da fixação de médicos, defende-se aqui que a Comissão Especial para a Elaboração de Diretrizes para um Plano de Carreira, Cargos e Salários para o SUS caminhe na direção apontada pelo representante e ex-presidente do Conasems na formulação do Pits, que, ao ser entrevistado para o estudo da Rede Observatório de Recursos Humanos em Saúde, propõe um plano de carreira nacional, mas com base local, ou seja, com ingresso por concurso público na instância municipal (Maciel Filho, 2007: 211). Isso possibilitaria que municípios menos atrativos também pudessem funcionar como porta de entrada para o profissional que deseje ingressar na carreira pública do SUS. Pode-se acrescentar a essa proposta a definição de faixas salariais compensatórias e ascenção funcional diferenciada para médicos e demais profissionais de saúde concursados nessas localidades.

Fica claro que a implantação do plano de carreira único do SUS e a incorporação de dispositivos nesse plano que contribuam para minimizar a má distribuição de médicos e ampliar a fixação desses 
profissionais dependem de acertos jurídicos e legais que os tornem viáveis no plano executivo. Isso só reitera a visão aqui defendida de que o enfrentamento do problema da má distribuição e fixação de médicos extrapola a política de recursos humanos em saúde e a própria política de saúde, devendo ser inserido na agenda do Estado e tratado no âmbito dos poderes Executivo, Legislativo e Judiciário, como parte do plano de desenvolvimento econômico e social do país. Tal inserção é indispensável para que possamos ultrapassar a lógica da 'atuação por programas' em direção à institucionalização de políticas consistentes, efetivas e de maior permanência.

\section{A Capacidade de Gestão dos Municípios}

Capacidade de gestão pública pode ser entendida como "a capacidade de realização, mediante estratégias e mecanismos descentralizados e democráticos voltados à provisão, manutenção e administração dos recursos e serviços públicos, com vistas ao desenvolvimento social (...)" (Lubambo, 1998: 4). Por sua natureza estrutural, a capacidade de gestão pública está relacionada a fatores de ordem econômico-fiscal e político-administrativa, que dizem respeito não apenas à capacidade de o gestor assumir os custos financeiros das funções sob sua responsabilidade, mas também à capacidade técnica de alcançar um bom desempenho. "Seguindo esta lógica, a variedade de situações municipais no que diz respeito à condição fiscal e à habilidade administrativa dos governos seria determinante da extensão e natureza da capacidade de gestão pública" (Lubambo, 1998: 4).

$\mathrm{Na}$ área da saúde, se por um lado foram ampliadas as responsabilidades sanitárias dos municípios, por outro ainda não foi oferecida, em níveis satisfatórios, contrapartida financeira e técnica que permita cumprir plenamente essas responsabilidades, nem houve completa delegação de autonomia gerencial e política: "tanto os governos locais quanto o chamado poder local têm dificuldades e constrangimentos impostos pela legislação nacional, que limitam o seu poder na condução das políticas de saúde" (Silva, 2001: 91). Além disso, a própria autonomia administrativa do governo municipal está “(...) claramente tolhida por determinantes econômico-estruturais, apesar da maior liberdade, formal, que passou a ter em relação ao governo central" (Silva, 2001: 107). 
A descentralização da saúde no país não resultou, automaticamente, na transferência de capacidade gestora para a esfera municipal (Brasil, 2005b), sendo possível constatar que “(...) habitualmente os municípios não têm capacidade de implementar as ações de governo condizentes com todas as responsabilidades que assumem" (Silva, 2001: 263).

Embora admitindo que a criação do SUS trouxe, efetivamente, uma ampliação do poder municipal, também se percebe que "o processo de descentralização implementado no Brasil a partir de 1987 é pleno de ambigüidades" (Campos, 1992: 97). A autonomia atribuída aos municípios pela legislação do SUS possibilitaria, teoricamente, que cada município pudesse compor o seu próprio modelo assistencial, desde que respeitadas algumas normas gerais. Mas essa 'autonomia relativa' acabou criando condições para a construção de distintas experiências locais, que variam conforme a linha política de cada governo, o quadro epidemiológico, a disponibilidade financeira e o grau de controle político que cada comunidade consegue impor à direção do sistema local, gerando um desenvolvimento heterogêneo entre os vários municípios (Campos, 1992).

Essa heterogeneidade pode ser atribuída, em grande parte, ao que Campos (1992: 99) identifica como "principal fator limitante do avanço da descentralização", que é "a dependência financeira do poder local dos governos dos estados e da União, já que vem se constatando que os recursos próprios dos municípios são insuficientes mesmo para o custeio do conjunto de serviços que lhes cabe executar". Basta lembrar que mais de $50 \%$ dos municípios brasileiros não arrecadam o suficiente para arcar com as despesas de suas estruturas administrativas e legislativas, e cerca de 2.000 municípios não arrecadam impostos federais (Mendes, 1998; Silva, 2001).

"É corrente no Brasil a noção de que, nas regiões mais pobres do país, esta pobreza econômica, estaria expressa numa forma de reduzida capacidade de gasto público" (Lubambo, 1998: 5). Isso significa entender que o gasto governamental é diretamente afetado pela base econômica, ou seja, pelo volume de riqueza a ser taxada, que representa a base fiscal da respectiva esfera de governo. "Associa-se, portanto, diretamente, possibilidades de bom desempenho na gestão à capacidade de gasto dos governos locais" (Lubambo, 1998: 5).

O que se tem hoje no Brasil são municípios alçados à condição de entes gestores autônomos, sem que ainda hoje o Estado brasileiro 
tenha conseguido promover, na maioria deles, as condições mínimas de infra-estrutura econômica e social para garantir o direito à saúde. Silva (2001: 86) lembra que

a municipalização da saúde no Brasil sofreu influências, também, da pletora de municípios que foram criados após a Constituição de 1988. O expressivo aumento de municípios na década de 90, determinado na maioria das vezes por interesses de grupos e facções políticas, transfere responsabilidades de gestão para muitos governos locais despreparados para cumprir seus deveres constitucionais.

Com isso, involuntariamente, a descentralização potencializou problemas crônicos e desencadeou a utilização de soluções gerenciais irregulares, a que os municípios recorrem não apenas em função de aspectos da própria política local, mas também por restrições legais, como, por exemplo, as definidas pela Lei de Responsabilidade Fiscal (Brasil, 2005b).

As dificuldades que os gestores municipais e de saúde enfrentam e que afetam sua capacidade de gestão geram problemas na relação com os profissionais, como atraso ou falta de pagamento de salários e precárias condições de trabalho.

Apesar de os municípios terem se constituído em atores relevantes na gestão do sistema de saúde, este movimento não foi suficiente para gerar mudanças significativas nas definições de política de recursos humanos neste nível. É impressionante a dissonância entre o dito e o praticado, entre as intenções professas e as realizações corriqueiras, produzindo muitas vezes o descrédito (Dal Poz, 1996: 134).

Esse cenário explica porque a coordenação nacional do Pits, ao comunicar que o Programa deixaria de existir e suas equipes seriam incorporadas aos sistemas municipais de saúde, viu imediatamente os profissionais reagirem e revelarem descrédito acerca da seriedade e capacidade de gestão dos municípios. Os profissionais referiram o receio de não mais receberem os seus salários em dia e de perderem o que denominaram 'imunidade política' contra as injunções do governo municipal, entre outras coisas. Esse receio parecia justificado quando, em muitos municípios, os profissionais do Pits verificavam as relações precárias de trabalho estabelecidas entre as prefeituras e os profissionais contratados para o sistema municipal de saúde e, ainda, atrasos no pagamento dos salários. 
No entanto, não se pode ignorar a advertência feita pelo representante e ex-presidente do Conasems, no estudo da Rede Observatório, de que se por um lado um programa federal para fixar profissionais, como o Pits, garante essa 'imunidade'; por outro, funciona como um elemento de distanciamento entre os profissionais e o gestor municipal, tornando-se uma estrutura paralela à Secretaria Municipal de Saúde (Maciel Filho, 2007: 199). Daí a compreensão de que a fixação de médicos nessas localidades não pode estar subordinada a uma lógica de programa federal, mas sim consolidar-se como parte da estrutura do sistema municipal de saúde a partir de uma política permanente e global na solução do problema, por meio de estratégias indutoras.

O fato de alguns municípios com esse perfil não conseguirem oferecer uma boa remuneração, cumprir os acordos trabalhistas, manter o pagamento dos salários em dia e proporcionar condições de trabalho adequadas justifica o descrédito e praticamente impede que sejam vistos pelos profissionais como locais onde construir uma carreira e se fixar. Por exemplo, as condições de trabalho oferecidas pelos gestores municipais aos profissionais do Pits, como cumprimento da contrapartida, foram, em muitos casos, insatisfatórias. Quase 70\% dos profissionais que responderam à avaliação do Ministério informaram não haver material, nem equipamentos suficientes para atendimento à população (Brasil, 2002e).

Esses fatores são conseqüência da baixa capacidade de gestão desses municípios, que, por sua vez, é causada pela deficiência técnica, pelas restrições financeiras e jurídicas e, por vezes, pelo que um dos formuladores do Pits denominou, como já referido, "visão política estreita de grande parte desses gestores, que administram os municípios como extensão de suas casas" (Maciel filho, 2007: 214). Isso é possível porque é "notório o predomínio do Poder Executivo nos sistemas locais. O arbítrio dos secretários e do prefeito é grande. Raramente outros sujeitos sociais conseguem contra-arrestar as políticas deliberadas pelo governo" (Campos, 1992: 106).

Por menos significativo que seja o município (em termos econômicos ou políticos), o poder do seu governante é expressivo, na medida em que este concentra em suas mãos a capacidade decisória sobre os mais importantes aspectos da produção e reprodução das atividades municipais (...) Articulados geralmente 
com as forças hegemônicas e controlando o legislativo local, os prefeitos exercem o seu poder praticamente sem contrapesos (principalmente nas pequenas cidades), o que lhes permite o controle e a centralidade das decisões, comumente apenas contrabalançada por restrições financeiras. (Lubambo, 1998: 10-11)

Além disso, verifica-se, ainda, que em muitos desses municípios os conselhos de saúde, quando existentes, "são uma extensão do Executivo, já que até mesmo os representantes dos usuários são de escolha das autoridades constituídas" (Campos, 1992: 105).

Mesmo os baixos salários e as insatisfatórias condições de trabalho - citadas freqüentemente como principais razões para que o profissional não queira trabalhar nesses municípios - são, em geral, considerados conseqüências diretas das deficiências políticas, organizacionais, sociais e econômicas, que incluem a cultura de clientelismo político (Dussault \& Franceschini, 2006).

Todos esses fatores, como visto, geram conflitos na relação entre os profissionais e os gestores municipais. Tais conflitos foram apontados pelos médicos do Pits como um dos principais motivos de desistências e desligamentos, aliados à dificuldade de adaptação às condições adversas dos municípios e à desorganização na condução do Programa.

A reversão desse quadro passa pelo investimento dos governos federal e estaduais no aperfeiçoamento da capacidade gestora desses municípios e pela ampliação e fortalecimento do controle social. Daí a importância da atuação efetiva dos conselhos de saúde, com acompanhamento mais sistemático por parte do Conselho Nacional de Saúde. Os melhores índices de desempenho de gestão pública tendem a ser encontrados nas esferas governamentais em que a tradição de participação política é mais forte e, contrariamente, quanto mais verticalizadas sejam as relações políticas, piores tendem a ser os índices de desempenho encontrados: "dito de outro modo, variações nos graus de desempenho da gestão estariam diretamente associadas a variações nos indicadores de participação política" (Lubambo, 1998: 7).

Sabe-se que, em um Estado federalista, a ação dos governos locais depende em grande parte da ação do governo federal, que pode induzir decisões e políticas públicas na esfera local. A habilidade políticoadministrativa, o desempenho de gasto e as relações e estratégias de articulação entre as esferas de governo são decisivas no desempenho da gestão. Nenhuma política que pretenda melhorar a distribuição de 
profissionais de saúde e ampliar sua fixação nessas localidades poderá ser bem-sucedida se os gestores municipais não forem capacitados para o exercício de suas funções, não contarem com investimento público e privado que proporcione maior aporte de recursos e se não forem ampliadas suas relações com a sociedade, por meio das instâncias de controle social, que podem tornar a gestão mais eficaz.

\section{A Formação dos Médicos}

As dificuldades de adaptação dos profissionais em atuar e viver nesses municípios podem ser, em grande medida, atribuídas ao distanciamento entre a educação médica e a realidade socioeconômica e sanitária do país.

O diagnóstico dessa cisão entre ensino médico e realidade social vem sendo reiterado há décadas. O modelo tradicional de ensino com base no hospital como locus privilegiado do processo de aprendizagem, muitas vezes desarticulado do sistema de saúde, não responde às necessidades de uma formação em que o princípio da integralidade da atenção é o alicerce das práticas de saúde (Maciel Filho, 2001). Este modelo é resumido por Silva (1986: 9-10) como acrítico, a-histórico e cientificista, no qual a “(...) falta de formação científica sólida, aliada à mitificação tecnológica e ao descompromisso social, transformam o médico formado num elo fundamental na cadeia do consumo de produtos (medicamentos) e equipamentos".

Atualmente, contudo, os ministérios da Saúde e da Educação vêm estudando critérios de atuação conjunta no credenciamento de cursos que considerem o papel regulador do Estado, a regionalização, a ampliação da rede pública de ensino e novas propostas pedagógicas.

Essas iniciativas, que deverão servir como subsídio para a proposta de Lei Orgânica da Reforma da Educação Superior, a ser apreciada pelo Congresso Nacional, “apontam a construção de processos regulatórios que podem reverter de fato as tendências observadas, que caracterizam o sistema de ensino no país como desordenado, desigual e privatizado" (Vieira et al., 2004: 200).

Já foi visto, no capítulo 1 , que o governo federal tem investido nessa direção, com iniciativas como a política de avaliação do funcionamento das escolas médicas, a criação do exame nacional para os graduandos, maior autonomia para as escolas na definição do 
currículo médico e a criação do Programa de Incentivo para Mudanças Curriculares para Faculdades de Medicina (Promed). Criado com a finalidade de incentivar transformações nos processos de formação, geração de conhecimentos e prestação de serviços à comunidade, por meio de inovações curriculares, de modo a propiciar profissionais habilitados para responder às necessidades do sistema de saúde brasileiro, o Promed estabelece mecanismos de cooperação entre os gestores do SUS e as escolas médicas; incorpora no processo de formação médica noções integralizadas do processo saúde-doença e da promoção de saúde; amplia a duração da prática educacional na rede de serviços básicos de saúde e favorece a adoção de metodologias pedagógicas, centradas nos estudantes, visando a prepará-los para a auto-educação continuada (Brasil, 2002a):

O que se busca é a intervenção no processo formativo para que os programas de graduação possam deslocar o eixo da formação centrado na assistência individual prestada em unidades hospitalares - para um outro processo em que a formação esteja sintonizada com o SUS, em especial com a atenção básica, e que leve em conta as dimensões sociais, econômicas e culturais da população, instrumentalizando os profissionais para enfrentar os problemas do binômio saúde-doença da população na esfera familiar e comunitária e não apenas na instância hospitalar. (Brasil, 2002d: 13-14)

Essas mudanças são imprescindíveis, porque, embora haja uma interação recíproca entre o sistema de educação médica e o sistema prestador de serviços, há razoável consenso acerca da existência de uma determinação mais forte da prática médica sobre a formação do recurso humano. Essa determinação se dá: 1) por meio da adoção de um determinado currículo em resposta à demanda do sistema de saúde por certo tipo de médico - como ocorre agora com o PSF e a criação do Promed; 2) na capacidade do sistema de saúde para tornar ou não viáveis as reformas propostas pelo sistema formador; 3) no fato de o sistema de saúde imprimir suas modalidades específicas aos programas educativos, ao prover espaços de prática para os educandos.

E se dessa vez as mudanças realmente parecem ter possibilidade de se efetivarem é devido ao fato de que o Promed é uma iniciativa que "pela primeira vez aponta não apenas uma direção concreta para as mudanças, respeitando as peculiaridades, idiossincrasias e autonomia 
de cada faculdade, mas também oferecendo recursos financeiros e consultorias para o processo (...)" (Rego, 2005: 43).

No entanto, mesmo considerando que o Promed possa vir a obter sucesso, não se pode ignorar que a mudança da formação médica é um processo bastante complexo, subordinado à estrutura econômica e social da sociedade onde está inserido. Nesse sentido, ainda que esse movimento para transformar a graduação médica cresça e se consolide - e em que pese a conformação do PSF como um novo mercado de trabalho -, há que considerar que

por um período de tempo significativo a grande maioria dos estudantes seguirá buscando especializar-se. Isso porque ainda não se transformou a imagem-objetivo de profissional bem-sucedido que a corporação e os estudantes de medicina têm: médico especialista, trabalhando meio tempo em um grande hospital privado e meio tempo em seu consultório particular. (Feuerwerker, 2001: 52)

Mesmo entendendo que o Promed pretende que a formação do médico seja adequada às necessidades de ampliação da atenção básica e da estratégia de saúde da família, abrindo mercado para o médico generalista, deve-se, contudo, destacar que a própria população não reconhece o médico não especialista, o mesmo ocorrendo com a corporação médica e mesmo com o CFM, que não tem registrada a prática do clínico geral, sendo a medicina interna a formação mais próxima do que propõem as novas diretrizes curriculares (Lampert, 2001). Em função disso, para que a mudança seja bem-sucedida, a população deve ser considerada e, portanto, instruída, para contribuir e prestigiar a iniciativa, e, para isso, o uso dos veículos de comunicação é fundamental (Lampert, 2001).

Estratégias para ampliar o reconhecimento e status social dos médicos generalistas que trabalham em áreas carentes e remotas têm sido implantadas em alguns países (Dussault \& Franceschini, 2006). Elas ajudam a levantar o moral desses profissionais e os estimulam a permanecer nessas áreas.

Na Austrália, há os clubes de saúde rurais, que funcionam nas universidades, sendo destinados aos alunos que possuam interesse em atuar posteriormente como profissionais nas áreas rurais e mais remotas (Cameron, 2002). Os clubes têm por objetivo proporcionar uma base social e de atividades profissionais para esses estudantes e o apoio mútuo. 
Na Tailândia, os médicos rurais criaram sua própria sociedade (The Rural Doctor Society), que proporciona programas inovadores para suporte ao trabalho nessas localidades. A sociedade foi muito bem recebida pelo público e pela corporação médica, tendo sido criada, inclusive, uma premiação por reconhecimento público, que elege o 'melhor médico rural do ano' e o 'melhor médico da área mais remota'. Alguns médicos recebem títulos honorários de mestre ou doutor, emitidos por universidades. Em nível nacional, os médicos rurais têm sido indicados à premiação como 'personalidade tailandesa do ano' (Wibulpolprasert, 1999, 2002).

Esse tipo de estratégia realmente parece surtir efeito, como visto na experiência do Pits, em que vários profissionais ressaltaram a relevância que atribuem ao Diploma de Serviços Prestados à Nação por terem participado do Programa e o orgulho em recebê-lo.

No Brasil, a crescente complexificação e tecnificação da prática médica e as notórias deficiências da graduação têm feito com que a formação de pós-gaduação seja encarada, tanto pela população quanto pelos próprios médicos, como um requisito indispensável para que o profissional conclua sua formação. O tipo de carreira a que o médico almeja e a conseqüente especialidade que irá escolher se converteram em elementos diferenciadores de sua posterior incorporação ao mercado de trabalho.

Isso leva a questionar se a formação em Saúde da Família deve ter também o caráter de uma especialização. Há mais de vinte anos, Ferreira (1983: 60) já alertava para os riscos aí embutidos e argumentava que esse poderia não ser o caminho mais adequado para se alcançar a desejável formação generalista para o médico:

É injustificável preparar um médico de família como especialista em nível de pós-graduação. Isto constitui, além de um contra-senso, uma falácia que pode conduzir a soluções contraproducentes. (...). se o excesso de especialização é criticado, não se pode reverter este excesso com a criação da medicina geral ou de família também em nível de especialidade. ${ }^{16}$

16 Tradução livre. 
Ao invés da criação de mais uma especialidade, o autor propunha que o médico de família fosse formado como resultado do próprio curso de graduação:

O nome que se dê a este profissional, seja médico de família, médico geral, ou qualquer outro, teria pouca importância, mas o que seria sim necessário assegurar é que sua preparação correspondesse ao próprio curso médico, a fim de poder ingressar no serviço imediatamente após sua graduação. ${ }^{17}$ (Ferreira, 1983: 60)

$\mathrm{O}$ autor entende que:

Ante a dificuldade de competir como médico geral desde o início da carreira na condição de profissional liberal, a opção não terá que ser necessariamente a da especialização precoce, mas o ingresso no sistema de serviços de saúde para prestar atenção primária. Eventualmente, inclusive, deveriam ser criados incentivos especiais para promover esta solução, com a possibilidade de emprego único e de sua oferta a todos os graduados de medicina geral, e o estabelecimento de mecanismos e graus de ascenção na carreira, sem necessidade de alijar-se desta orientação geral. ${ }^{18}$ (Ferreira, 1983: 60)

As ponderações de Ferreira nos remetem à experiência do Chile, onde foi criada uma carreira específica para médicos que se propunham a trabalhar nas áreas mais carentes e distantes. No entanto, quando o governo militar descentralizou o Sistema Nacional de Saúde chileno e transferiu para os municípios a responsabilidade pela atenção básica, esses médicos tornaram-se funcionários municipais, sendo desvinculados da estrutura hospitalar do Ministério, que lhes garantia educação continuada. O cargo tornou-se menos atrativo, aumentando o número de vagas não preenchidas, o que fez com que se estudasse a criação de um novo regime administrativo, para os profissionais de saúde municipais, que garantisse a educação de pós-graduação e uma carreira em atenção básica (Herrera \& Corral, 1995; Opas/OMS, 1998).

Em um modelo em que, ao término da graduação, o médico esteja apto a atuar na atenção básica, como se espera com as novas diretrizes curriculares, as especialidades

17 Tradução livre.

18 Tradução livre. 
devem ficar definidas em função da divisão racional das áreas de ampliação científica e desenvolvimento de tecnologias médicas de ponta, com vistas ao suporte e referência dos serviços de baixa e média complexidade. Nesta lógica, o bom generalista, especialista e superespecialista, são igualmente imprescindíveis, desde que adequadamente distribuídos e articulados no processo de trabalho e de oferta das ações de saúde à população de cada região. (Santos, 2001: 143)

A tendência à especialização pode anular o impacto dos processos de mudança na graduação, como os que têm sido implantados por meio do Promed (Padilha \& Feuerwerker, 2002). Em consonância com esse conjunto de argumentos, o que aqui se defende é a formação do médico de família como resultado do próprio curso de graduação, entendendo que o Promed e as novas diretrizes curriculares representam, efetivamente, a possibilidade de que o curso de medicina assegure terminalidade para a formação do profissional médico.

Isso significa formar médicos, que, ao término do curso, estejam aptos para ingressar no mercado de trabalho de saúde da família, e que, pela competência adquirida na graduação, sejam prestigiados e respeitados pela corporação e por todos os demais segmentos da sociedade.

\section{A Distribuiç̧ão das Escolas Médicas}

A formação de recursos humanos para a saúde e a criação de instituições formadoras devem ser responsabilidade dos governos, como resultado de políticas de saúde e de educação explícitas. Todavia, no que se refere ao modelo de ensino médico, se por um lado, o Promed vem atender a uma expectativa e a uma necessidade antigas; por outro, no que diz respeito à criação de novas escolas médicas, o cenário ainda é preocupante. $\mathrm{O}$ que se tem verificado é o aumento do número de escolas médicas e o crescimento desordenado dos programas de residência, sem que ambos estejam efetivamente orientados pelas necessidades do sistema de saúde e do modelo de atenção.

Como já discutido no primeiro capítulo, as escolas médicas estão fortemente concentradas nas regiões Sudeste e Sul, e a expansão de cursos médicos nessas áreas "obedeceu muito mais ao desenvolvimento econômico e ao poder de compra dessas regiões do que às reais 
necessidades de acesso ao ensino superior nas regiões desprovidas de infra-estrutura como o Norte e o Nordeste" (Vieira et al., 2004: 192).

O tema tem preocupado os formuladores de políticas, gestores do setor e demais atores. E não apenas no que se refere à má distribuição da oferta de cursos de graduação de medicina, mas de toda a área da saúde. Recentemente, o documento preparatório para a $3^{\text {a }}$ Conferência Nacional de Gestão do Trabalho e da Educação na Saúde, publicado em 2005, destacou "a necessidade de formular critérios nacionais para a abertura de cursos e de vagas nas escolas, a serem respeitados por todas as instâncias do setor da educação", entendendo que "não se pode concordar que sejam abertos cursos em regiões carentes sem um processo seletivo que conceda elevada prioridade aos candidatos locais" (Brasil, 2005b: 48).

Não fica claro, no documento, o que se entende por "um processo seletivo que conceda elevada prioridade aos candidatos locais". Entretanto, já há várias décadas, diversos estudos internacionais têm demonstrado que candidatos ao curso de medicina provenientes de áreas rurais têm maior tendência a se interessarem por atuar nessas áreas, comparativamente àqueles oriundos de áreas metropolitanas, desde que estimulados por uma política de admissão à graduação, por incentivos curriculares durante o curso etc. (Carter, 1987; Cullison, Reid \& Colwill, 1976; Johnson, Baeumler \& Carter, 1973; Kassebaum \& Szenas, 1993; Leonardson, Lapierre \& Hollingsworth, 1985; Rabinowitz, 1993; Rabinowitz et al., 1999).

Cullison, Reid e Colwill (1976: 504), por exemplo, afirmam que

apesar da escolha do local de prática ter muitos determinantes, muito poucos deles podem ser influenciados pela escola médica. (...) No que se refere à admissão à escola médica, a ênfase crescente na seleção de pretendentes qualificados com origens rurais pode incrementar a porcentagem de graduados da escola médica que estejam interessados em atuar em área não metropolitana ou metropolitana de pequeno porte (...). ${ }^{19}$

A fim de aumentar o número de estudantes de medicina oriundos das áreas rurais, esses autores propõem que as escolas médicas não apenas incrementem o grau de aceitação de candidatos dessas áreas

19 Tradução livre. 
que possuam qualificação, mas também implementem programas de recrutamento de estudantes das áreas rurais. Vários países têm adotado essa estratégia, como Austrália, Estados Unidos e Tailândia (Wibulpolprasert, 2002).

Por fim, os autores concluem que:

Os dados de diversos estudos sugerem que programas comuns que aumentam o número de estudantes médicos originários dos condados não metropolitanos e incrementam oportunidades para esses estudantes na medicina de família podem propiciar um impacto importante sobre a carência de médicos rurais. ${ }^{20}$ (Cullison, Reid \& Colwill, 1976: 505)

Rabinowitz (1993) avaliou os resultados de um desses programas, desenvolvido na Pensilvânia, Estados Unidos. O Programa, denominado "Physician Shortage Area Program" (PSAP), foi implantado em 1974, pelo Jefferson Medical College of Thomas Jefferson University, uma universidade privada, e se propõe a recrutar e admitir candidatos à escola médica, oriundos de áreas rurais, que pretendam atuar como médicos de família em localidades rurais ou desprovidas de atendimento médico. Além de apoio financeiro, os estudantes contam com um programa curricular específico em medicina de família, incluindo um supervisor, atividades obrigatórias no terceiro ano em uma ou duas localidades não metropolitanas e um semi-internato em medicina de família com preceptoria de um médico de família.

Rabinowitz analisou, por meio de dois estudos, os resultados obtidos pelo PSAP após 18 anos de sua implantação (Rabinowitz, 1993), e, posteriormente, após 22 anos da implantação (Rabinowitz et al., 1999). O autor se reporta a outros estudos, como o de Pathman, Konrad e Ricketts III, (1992), que já mostravam que os médicos graduados pelo PSAP registram um ingresso em medicina de família cinco vezes superior ao daqueles que não se graduaram pelo Programa e que sete em cada dez graduados do PSAP aliam a prática em medicina da família com a atuação em áreas não metropolitanas ou desprovidas de médicos. Os dois estudos de Rabinowitz confirmam e estendem esses resultados, mostrando que os graduados do PSAP continuam ingressando muito mais na medicina de família em áreas rurais ou

20 Tradução livre. 
carentes do que seus pares. Registram, além disso, alto grau de retenção nessas áreas em comparação com outros programas vigentes nos Estados Unidos, como o National Health Service Corps (NHSC), que oferece bolsas de estudo ou crédito educativo a estudantes que se proponham a atuar em áreas, designadas pelo governo, com carência de médicos. Concluem tratar-se de um Programa muito bem-sucedido e com resultados de longo prazo, que deve ser implementado por outros estados norte-americanos (Rabinowitz, 1993; Rabinowitz et al.,1999).

Rabinowitz (1993) observa, ainda, que, embora não tenham sido avaliados isoladamente os vários componentes do PSAP (admissão, ajuda financeira, supervisão, currículo e locais de prática), a admissão seletiva parece ser o fator mais poderoso para o sucesso do Programa,

uma vez que dados nacionais indicam que estudantes com origem rural ou interesse em medicina de família que entram para a escola médica estão muitas vezes mais próximos do que seus pares de se tornarem médicos de família ou atuarem em áreas rurais (e aqueles não interessados em medicina de família ou na prática rural são altamente improváveis de mudar sua escolha de carreira para a medicina de família). ${ }^{21}$ (Rabinowitz, 1993: 938)

Além disso, Rabinowitz e seus colaboradores argumentam que mais de $2 / 3$ dos graduados pelo PSAP não haviam sido aceitos por nenhuma outra escola médica além da Jefferson Medical College. Os dados da revisão de todos os matriculados da Jefferson Medical College, durante os 22 anos analisados pelo estudo, mostram que uma proporção similar de alunos não teria sido aceita pela própria Jefferson Medical College se o Programa não existisse. No entanto, verifica-se que o desempenho desses estudantes durante o curso foi semelhante a de seus colegas de classe não participantes do PSAP (Rabinowitz et al., 1999).

O autor acrescenta que outros programas têm alcançado metas semelhantes, o que sugere que as "escolas médicas podem ter uma influência substancial na distribuição geográfica e de especialidades de seus graduandos". Rabinowitz adverte, no entanto, que as

escolas médicas não podem solucionar o problema nacional da má distribuição de médicos, por si sós. Mudanças são também

21 Tradução livre. 
necessárias na abordagem da educação superior médica, na remuneração dos médicos da atenção primária, no processo de crédito educativo e nas condições de exercício profissional. ${ }^{22}$ (Rabinowitz, 1993: 939)

De qualquer forma, em outro estudo que discute os fatores críticos a serem considerados para o desenho de programas que tenham como objetivo aumentar a oferta e retenção de médicos na atenção primária em áreas rurais, Rabinowitz et al. (2001) reiteram a conclusão de que os educadores médicos e os formuladores de políticas podem obter um grande impacto se implantarem programas que incrementem o número de estudantes médicos de origem rural e planos de carreira na medicina de família. Estudos desenvolvidos por outros autores reforçam essa conclusão (Curran \& Rourke, 2004; Dunbabin \& Levitt, 2003; Jackson \& Jackson, 1991; Kamien \& Buttfield, 1990; Vaneslow, 1990).

Curran e Rourke (2004: 266) também entendem que:

A educação médica tem um importante papel a desempenhar no recrutamento de médicos rurais. A organização, localização e missão das escolas médicas têm se mostrado relacionadas com a propensão dos graduandos a selecionarem a prática rural. Escolas médicas que são descentralizadas, localizadas em áreas rurais, possuem um foco rural, encorajam a admissão de estudantes rurais, facilitam o currículo médico voltado para a atuação rural e que proporcionam desde cedo experiências de aprendizado em medicina rural, são as mais bem-sucedidas em graduar médicos que irão escolher a prática rural como carreira. ${ }^{23}$

Os autores reportam três exemplos internacionais de escolas médicas com essas características e orientações: Tromso, no nordeste da Noruega; Jichi Medical School, no Japão; e Memorial University, em St John's, Canadá.

Na Tailândia, o recrutamento de estudantes rurais tem sido feito por algumas escolas médicas, com relativo sucesso. Tais escolas, espalhadas pelo país e subsidiadas, formam, anualmente, cerca de 300 médicos especificamente para atuar nas áreas rurais. Uma rede de hospitais e clínicas locais onde os estudantes podem praticar foi

22 Tradução livre.

23 Tradução livre. 
montada para dar suporte ao Programa. Os estudantes desenvolvem essa prática nas localidades onde irão trabalhar após a graduação, o que é definido em contrato quando são recrutados, com vigência de dois a quatro anos. O Programa tem aumentado, consideravelmente, a proporção de alunos de medicina de origem rural (Wibulpolprasert, 1999, 2002).

Os estudantes de origem rural estão sub-representados nas escolas médicas relativamente à população rural total, o que caracteriza a dificuldade de acesso dessa população ao ensino médico (Curran \& Rourke, 2004). Diversos estudos confirmam esse cenário (Head \& Harris, 1989; Hutten-Czapski \& Thurber, 2002; Kamien \& Buttfield, 1990; Kassebaum \& Szenas, 1993; Rourke, 2005).

Com freqüência, as comunidades rurais possuem menor nível educacional do que as urbanas. Dessa forma, por falta de modelos, os jovens que residem nas áreas rurais têm menos incentivo e experimentam menos aceitação à idéia de cursar uma faculdade, incluindo a escola médica, do que seus pares urbanos (Dhalla et al., 2002). Além disso, a renda familiar nas regiões rurais é significativamente mais baixa do que a verificada nos centros urbanos, o que faz com que o alto custo da escola médica se configure como uma barreira real para os estudantes dessas áreas. A conclusão a que se chega é que há um viés no processo de admissão à escola médica que, não intencionalmente, dificulta a entrada de estudantes das áreas rurais (Rourke, 2005).

Variadas estratégias têm sido utilizadas para ampliar esse acesso. Na Austrália e nos Estados Unidos foram implementadas políticas que incluem criação de vagas, pontuação diferenciada nos processos seletivos, bolsas de estudo e apoio financeiro (Rourke, 2005). Recentemente, a Sociedade de Médicos Rurais do Canadá divulgou um relatório com recomendações de políticas e estratégias para ampliar o acesso dos estudantes rurais à formação médica, que inclui iniciativas destinadas a fomentar, desde o ensino básico, o interesse pelo estudo da medicina (Rourke, 2005). No México e na Tailândia, os estudantes que recorrem ao crédito educativo para cursar medicina podem pagar seus estudos por meio do trabalho, após a graduação, em áreas rurais com carência de médicos, definidas pelo governo (Dussault \& Franceschini, 2006). 
Os jovens das áreas rurais que conseguem ultrapassar essas dificuldades ainda precisam arcar com elevados custos de deslocamento em função das grandes distâncias que, em geral, separam essas localidades dos centros urbanos onde estão localizadas as escolas médicas (Rourke, 2005). Dussault e Franceschini (2006) mostram que a localização da escola médica está associada com a escolha do local de prática e da especialidade.

No Brasil, o cenário não é diferente e se estende à formação em nível de pós-graduação. Feuerwerker (2001: 51), por exemplo, lembra que "o fato de o médico recém-formado fazer residência fora do seu local de origem é um importante fator de concentração dos médicos nos principais centros urbanos e especialmente na região Sudeste". Afirmação confirmada pelo estudo de Machado (1997), que mostra que $60 \%$ dos médicos que migram para fazer residência médica não retornam ao seu local de origem. Estudos internacionais, já há algumas décadas, também demonstram o mesmo (Holmes \& Miller, 1986; Johnson, Baeumler \& Carter, 1973; Leonardson, Lapierre \& Hollingsworth, 1985; Yett \& Sloan, 1974).

O estudo de Machado (1997) permite observar também que a localização de escolas de medicina em municípios do interior contribui para que os profissionais que ali se graduam acabem fixando residência em localidades do interior do país. Somente para o estado do Rio de Janeiro essa tendência não se revelou válida, uma vez que independentemente da localização do estabelecimento de ensino, os médicos formados terminam por se fixar nas capitais. As conclusões da autora confirmam a literatura internacional, que mostra a tendência dos médicos em permanecerem nas áreas onde se graduaram ou se especializaram (Burfield, Hough \& Marder, 1986; Cooper, Heald \& Samuels, 1977; Kristiansen \& Førde, 1992; Leonardson, Lapierre \& Hollingsworth, 1985; Scheffler, 1971; Watson, 1980). Recentes estudos nacionais também chegam às mesmas conclusões (CFM, 2004; Pinto, 1999; Póvoa \& Andrade, 2006), o que deixa clara a importância da distribuição espacial das escolas de medicina para uma distribuição mais equânime de médicos no país.

Conforme demonstrou a experiência do Pits, foi a Região Nordeste que se destacou como região de graduação da maioria dos médicos lotados no Programa, dos que concluíram um ano de participação e dos que renovaram por mais um ano. Já o Sudeste apresentou um 
índice como região de graduação dos médicos desistentes ou desligados $(37,4 \%)$ bastante superior à sua participação como região de graduação dos que concluíram um ano $(25,6 \%)$ ou renovaram $(16,2 \%)$. Além disso, também foi expressivo o percentual de médicos que concluíram um ano no Pits e haviam se formado em instituições de ensino superior da Região Norte (19,7\%), que foi o local de origem de 19,8\% dos médicos lotados, levando à conclusão de que os médicos oriundos da Região Norte ali se graduaram. Deve-se relembrar, ainda, que a maioria dos médicos que concluíram um ano no Pits ou renovaram sua participação era proveniente das regiões Nordeste e Norte $(68,7 \%$ e $73 \%$, respectivamente).

Vale, portanto, destacar a conclusão obtida por meio desses e de outros dados do Pits: há maior interesse, por parte dos médicos que já residem e se graduaram nas regiões Nordeste e Norte, de fixação nessas localidades consideradas menos atrativas para aqueles do Sudeste, Sul e Centro-Oeste. Desde que, é claro, sejam oferecidas condições adequadas de contratação, remuneração, capacitação e incentivos compensatórios. Além do maior interesse, esses profissionais revelaram particular sensibilização com as condições de vida e de saúde da população dos estados e regiões em que vivem, mostrando-se mais conhecedores dos problemas e limitações existentes e mais conscientes e mobilizados em reverter o quadro de saúde que afeta as comunidades dessas áreas.

Esses resultados são convergentes com os de estudos internacionais que mostram que graduados oriundos de escolas médicas localizadas fora dos grandes centros urbanos são mais propensos a atuar em áreas rurais e a escolher especialidades ligadas à atenção básica, tais como a medicina de família (Rosenblatt et al., 1992).

No caso do Brasil, a possibilidade de que esses estudantes possam graduar-se em universidades em seus próprios estados de origem e dar continuidade a sua formação nessas localidades vem se tornando factível apenas há alguns poucos anos. Como visto no capítulo 1, até pouco tempo, a maioria desses profissionais precisaria deslocar-se para as demais regiões do país - particularmente para o Sudeste e o Sul para se graduar em medicina. Hoje, o Norte e o Nordeste contam com cerca de $31 \%$ das escolas médicas do país, sendo que mais da metade delas (54\%) foram criadas nos últimos seis anos, ou seja, a partir do ano 2000. O impacto que a criação dessas escolas poderá ter sobre a 
má distribuição e a maior fixação de médicos nessas regiões só poderá ser avaliado dentro de mais alguns anos. Mas, de qualquer forma, a abertura de vagas para medicina nessas áreas parece indispensável como uma das estratégias para enfrentar o problema e se mostra compatível com o que aponta a literatura internacional. Isso não significa defender uma visão expansionista de formação de médicos, mas ao contrário, visa a estimular a reflexão acerca da reversão dessa tendência, em favor de políticas que: 1 ) reorientem a criação de escolas médicas num sentido que favoreça a distribuição geográfica e a fixação desses profissionais em localidades de menor porte; 2) estabeleçam processos seletivos que incentivem o ingresso de estudantes rurais; 3 ) criem oportunidades de educação continuada e atualização profissional em localidades próximas a essas áreas.

\section{O Movimento Migratório dos Médicos}

A distribuição geográfica de médicos está fortemente condicionada pelo processo de escolha da localidade em que esse profissional pretende atuar, que, por sua vez é influenciada por diversos fatores, alguns específicos desta categoria profissional; outros inerentes ao próprio movimento migratório em geral.

Os fatores envolvidos na decisão que leva os indivíduos a migrarem de uma área para outra estão vinculados à identificação de aspectos positivos e negativos nas áreas de origem e de destino, conhecidos como fatores de atração ou de expulsão (Lavinas, Carleial \& Nabuco, 1994; Patarra, 1997; Santos, Levy \& Szmrecsányi, 1991; Singer, 1972). É, portanto, uma decisão seletiva que cria correntes e contracorrentes de fluxo migratório, com especificidades por escolaridade, sexo, idade, ocupação etc (Pacheco \& Patarra, 1997; Pinto, 2000).

O fenômeno migratório é parte de um processo mais amplo de transformação global da própria sociedade, sendo possível diferenciar os fatores de atração ou expulsão segundo seu caráter de 'causas' entendidas como condições estruturais - ou de 'motivos' - entendidos como condições individuais ou familiares (Singer, 1972).

Póvoa e Andrade (2006), com base em modelo teórico proposto por Maier e Weiss (1991), realizaram um estudo de modelagem considerando diversas variáveis que funcionam como 'causas' ou 
'motivos' para a migração de médicos no Brasil. O estudo confirma os achados de Rosko e Broyles (1988), para quem os médicos são atraídos para as regiões onde os ganhos líquidos sejam altos. Segundo esses autores, o maior número de médicos em uma localidade aumenta a competitividade e diminui os ganhos líquidos, tornando-a menos atrativa, segundo este critério.

No entanto, como foi possível observar na experiência do Pits, mesmo com a boa remuneração oferecida e acrescida do incentivo financeiro criado pelo Ministério da Saúde para este fim, poucos profissionais optaram por renovar sua participação no Programa. Isso parece indicar que, em se tratando de interiorização, não é o atrativo financeiro que tem maior peso na decisão dos médicos de aceitarem trabalhar nessas localidades.

Dentre os fatores que podem ser classificados como 'motivos', a literatura revela que a influência do cônjuge tem papel de destaque na escolha dos médicos por uma cidade para migrar (Holmes \& Miller, 1986; Kazanjian \& Pagliccia, 1996; Leonardson, Lapierre \& Hollingsworth, 1985; Póvoa \& Andrade, 2006; Szafran, Crutcher \& Chaytors, 2001). São estudos que mostram que as localidades com mercado de trabalho restrito e com poucas oportunidades são preteridas pelos parceiros conjugais dos médicos - particularmente quando possuem bom nível de escolaridade - por verem suas próprias perspectivas profissionais reduzidas. Em recente trabalho, Pinto (2000) mostra que $26,9 \%$ do total de médicos em atividade no país migram por motivos familiares; $25,7 \%$ em busca de formação profissional e $24,4 \%$ por melhores condições de trabalho.

A modelagem de Póvoa e Andrade (2006) também aponta nessa direção, além de revelar que os médicos mais jovens são mais propensos a migrar, reduzindo-se a partir dos 50 anos o interesse em se deslocar. No entanto, no caso do Pits, o expressivo percentual de 23,2\% dos lotados tinham mais de 50 anos, e parte desses profissionais optaram por atuar no Programa em busca de um estilo de vida mais interiorano e distante do estresse das grandes cidades. Foram também os médicos mais velhos que, em geral, optaram por continuar no Programa por pelo menos mais um ano.

Outros estudos apontam que as mulheres demonstram menos interesse em atuar nas áreas rurais do que os homens (Bowman \& Gross, 1986; Doescher, Ellsbury \& Hart, 2000). Dessa vez o caso do Pits 
confirma o achado, revelando que tanto os médicos que se inscreveram para participar do Programa quanto os que desistiram antes da lotação e os efetivamente lotados eram, em sua maioria, do sexo masculino. Além disso, o maior percentual de desistências e desligamentos foi registrado entre as mulheres. São necessários estudos mais detalhados e específicos para identificar as causas desse fenômeno.

Leonardson, Lapierre e Hollingsworth (1985), utilizando técnicas de regressão múltipla, pesquisaram 29 variáveis que podem interferir na escolha do local de atuação dos médicos, destacando como principais: o tamanho da cidade onde o profissional cresceu; o tamanho da cidade onde o(a) esposo(a) ou companheiro(a) cresceu; o contato com outros médicos; a importância que o profissional atribui à educação médica continuada; as oportunidades de crescimento profissional. Os autores concluem que as percepções e preferências de estilo de vida dos médicos são os principais fatores para determinar o local de atuação.

Com relação ao quarto fator anteriormente apontado, a educação médica continuada -, foi possível observar, na experiência do Pits, que, em sua maioria, os médicos que se inscreveram no Programa não haviam feito nenhum curso de pós-graduação, e que o curso de especialização em saúde da família foi considerado por eles como o fator mais atrativo do Programa. Foram exatamente profissionais sem pós-graduação que, majoritariamente, renovaram sua participação por mais um ano Além disso, a quase totalidade dos médicos que participaram do Pits declarou necessidade de aprimoramento profissional.

Page et al. (1992) também se dedicaram à pesquisa de fatores que interferem na escolha dos médicos pelo local de atuação. Os autores identificaram fatores atrativos e negativos em relação às áreas rurais. Como fatores negativos, foram citados pelos profissionais: a ausência de outros médicos com quem possam interagir; a inexistência de supervisores; a falta de especialistas de referência para onde encaminhar os pacientes; a falta de equipamentos e de recursos para manutenção; a falta de apoio laboratorial; as longas distâncias dos centros urbanos; as dificuldades de transporte; a escassez de opções de lazer. Mas o fator mais referido como motivo para não haver interesse pela escolha de áreas rurais foi a falta de oportunidades de pós-graduação. Como aspectos atrativos que mobilizam os profissionais para atuar nessas 
áreas foram identificados: menor taxa de violência; menos poluição; desejo de mudança; sentimentos altruístas. Em relação aos 'sentimentos altruístas', no caso do Pits, 'a atuação profissional junto às comunidades carentes' foi considerada pelos médicos como o fator mais satisfatório do Programa.

Szafran, Crutcher e Chaytors (2001), por sua vez, encontraram resultados semelhantes aos estudos de Leonardson, Lapierre e Hollingsworth (1985) e Page et al. (1992), destacando ainda as condições de remuneração, incentivos financeiros, a disponibilidade de educação médica continuada, as oportunidades educacionais para os filhos e a proximidade da família e dos amigos.

No Brasil, o crescente processo de industrialização e urbanização, intensificado a partir da década de 1950, tornou as regiões Sudeste e Sul pólos de atração de profissionais dos mais variados segmentos, não apenas pela maior oferta de trabalho, mas também pelas oportunidades educacionais.

Analisando a origem geográfica dos médicos que trabalham nas diversas regiões brasileiras, Machado (1997), a partir do já citado "Perfil dos médicos no Brasil", realizado em 1995, aponta as especificidades do movimento migratório desses profissionais. As regiões Nordeste, Sudeste e Sul comportam-se como mercados de trabalho mais fechados regionalmente, com mais de $73 \%$ de seus médicos sendo oriundos da própria região. O Centro-Oeste revela-se como o mercado mais dependente de profissionais de outras regiões $(68,8 \%)$, seguido da Região Norte (39\%). A análise por Unidade da Federação (UF) mostra que, com exceção do Pará, os demais estados da Região Norte dependem fortemente do aporte de médicos vindos de outros estados do país. Já o Rio Grande do Sul e Minas Gerais são os que possuem a menor participação de médicos migrantes - 5,7\% e 13,1\%, respectivamente -, acentuando a característica de mercados fechados, constituídos de profissionais nascidos na própria localidade.

Machado (1997: 42), com base em mapas migratórios entre as UFs, elaborados a partir do estudo que coordenou, resume assim as principais características observadas no movimento migratório dos médicos entre os diversos estados brasileiros:

Minas Gerais se destaca como um 'estado migrador', seguido de Rio de Janeiro e São Paulo, fato explicado em parte pela alta 
concentração de escolas médicas nesses estados. Apenas um estado nordestino - Pernambuco - figura entre os estados de maior volume migratório, mesmo assim localizado apenas no movimento de migração Pernambuco-Roraima. Paradoxalmente, a totalidade dos estados que compõem a região Nordeste apresenta as menores taxas de migração de todo o país, o que sugere um mercado fechado e tipicamente nordestino, onde as trocas de serviços e profissionais especializados são realizadas no interior da própria região.

Pinto (2000: 54), por sua vez, sintetiza as principais características do movimento migratório desses profissionais:

Médicos tendem a se especializar e em boa medida acabam buscando centros urbanos desenvolvidos a fim de se 're-qualificarem' para os novos desafios e perspectivas profissionais; médicos consideram os 'fatores de atração' que um determinado município de um estado possa oferecer e isso influencia sua decisão de migrar; médicos formam movimentos migratórios de correntes e contracorrentes diferenciados por especialidade, faixa etária e gênero; médicos analisam, no plano individual, os custos e benefícios de migrar, levando em consideração, por exemplo, os rendimentos que irão auferir, estando estes situados, de maneira geral, acima da média salarial dos demais profissionais não-migrantes.

De qualquer forma, ainda é muito reduzido o contingente de médicos que optam por atuar no interior. No caso dos egressos de universidades federais, por exemplo, apenas $14 \%$ dos que se graduaram no estado do Rio de Janeiro, 8\% no Pará, 7\% em Pernambuco, 4\% no Ceará e no Rio Grande do Norte e $2 \%$ em Alagoas, se deslocaram para o interior (Machado, 1997). Mas a competitividade cada vez maior do mercado de trabalho nos grandes centros urbanos tende a acarretar, gradativamente, maior movimento migratório para cidades do interior que ofereçam condições para o exercício da medicina, conforme demonstra a experiência de outros países (Newhouse et al., 1982; Nocera \& Wanzenried, 2002; Schwartz et al., 1980; Williams et al., 1983).

Entende-se aqui que a diversidade de 'causas' e 'motivos' que interferem nesse cenário mostra o quanto é complexo e multifacetado o problema da má distribuição de médicos. Para enfrentá-lo, sugere-se que além de políticas que contemplem as considerações e recomendações defendidas nos eixos analíticos anteriores, sejam 
adaptadas iniciativas como as que foram implementadas na Austrália. O governo e alguns estados australianos têm fundado organizações nãogovernamentais, conhecidas como Agências de Força de Trabalho Rural, para incrementar o recrutamento de médicos rurais e estimular sua permanência nessas localidades (Cameron, 2002). A principal estratégia adotada é a garantia de educação continuada, aliada a gratificações financeiras, sistema de referência e contra-referência, manutenção de uma rede de comunicação e de troca permanente de experiências entre esses profissionais e mediação em caso de atritos entre colegas ou com as autoridades locais. Além disso, reconhecendo a importância da influência e satisfação da família para que os médicos se fixem nessas localidades, foram implementadas estratégias de apoio às suas famílias, incluindo a criação da Rede de Famílias de Médicos Rurais, que proporciona suporte para as possíveis dificuldades de adaptação. 